\title{
Crescent sign in abdominal aortic aneurysm
}

\author{
Pooya Iranpour, Sara Haseli
}

Radiology Department, Shiraz University of Medical Sciences, Shiraz, Iran

\section{Correspondence to}

Dr Pooya Iranpour, pooya.iranpour@gmail.com

Accepted 18 May 2018

\section{DESCRIPTION}

A 70-year-old man referred to emergency department with acute onset of severe flank pain. In initial examinations, the patient was pale, with pulse rate of $120 / \mathrm{min}$ and blood pressure of $95 / 65$. In abdominal palpation a pulsatile mass was detectable. Urgent resuscitation was done.

The patient had been known to have hypertension and abdominal aortic aneurysm (AAA) since 7 years ago. Abdominal CT scan without and with contrast injection (figures 1 and 2) showed a large fusiform abdominal aorta with crescentic focus of hyperdensity (black arrow) within the mural thrombus (white arrow), known as high-attenuating crescent sign. Retroperitoneal haematoma was also observed anterior to psoas muscles bilaterally (asterisks). Endovascular repair was chosen as an emergent surgical procedure. The patient was discharged on postoperative day 7 , and recovery was uneventful.

High-attenuating crescent sign is intramural or mural thrombus haemorrhage of an abdominal aneurysm and means impending or acute aortic aneurysm rupture.

AAA rupture has high mortality rate even with emergent surgical repair; so prompt correct diagnosis is necessary for proper management. There are several predictive factors in AAA rupture, such as large size of the aneurysm, rapid increase in diameter, focal wall discontinuity and crescent sign. Crescent sign - an indicator of AAA complication and impending rupture-has high specificity and positive predictive value of $77 \%$ and $93 \%$, respectively. ${ }^{2}$

The pathophysiology of this sign is dissecting blood through mural thrombosis or wall of the aneurysm resulting in weakening of the wall. It is of

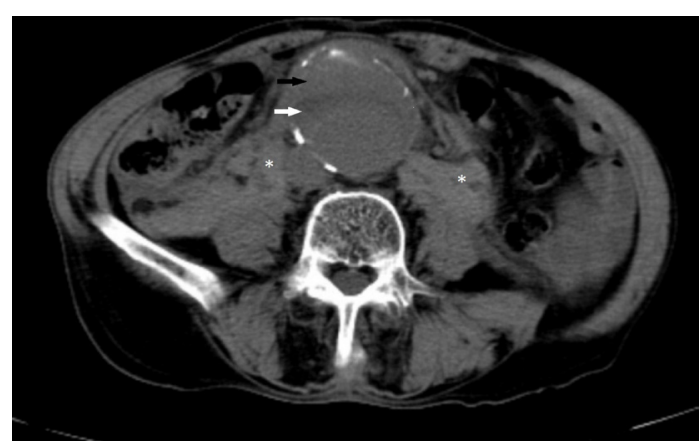

Figure 1 Non-contrast enhanced abdominal CT scan shows an abdominal aorta aneurysm with mural thrombosis (white arrow) and crescent sign (black arrow).

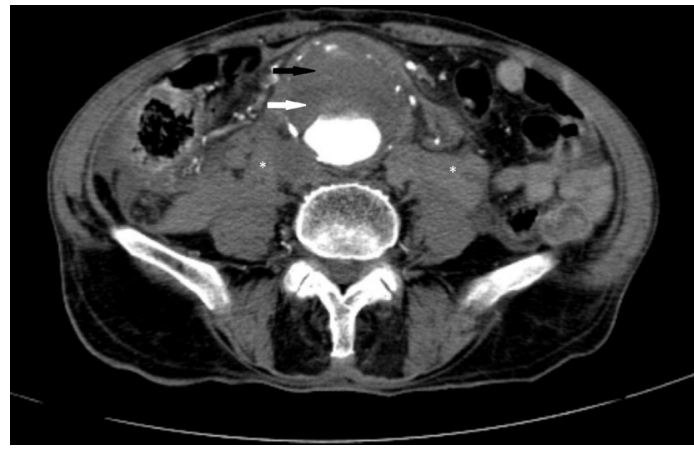

Figure 2 After injection of contrast patent lumen of the aneurysm is opacified. Hyperdense crescent sign is visible as rim of increased density (black arrow) within the mural thrombus (white arrow), relatively hyperdense compared with psoas muscles. Retroperitoneal haematoma is visible anterior to psoas muscles (asterisk).

relatively high density compared with psoas muscle in contrast-enhanced CT scan and is greater than aorta in non-contrast CT images. ${ }^{3}$

\section{Learning points}

- Hyperdense crescent sign is due to haemorrhage into the wall of aneurysm or within the mural thrombosis.

- Hyperdense crescent sign indicates impending aneurysm rupture.

Contributors PI has planned the work and provided the case and critically reviewed the article. SH has performed the literature review and has written the article.

Funding The authors have not declared a specific grant for this research from any funding agency in the public, commercial or not-for-profit sectors.

Competing interests None declared.

Patient consent Next of kin consent obtained.

Provenance and peer review Not commissioned; externally peer reviewed.

(C) BMJ Publishing Group Ltd (unless otherwise stated in the text of the article) 2018. All rights reserved. No commercial use is permitted unless otherwise expressly granted.

\section{REFERENCES}

1 Gonsalves CF. The hyperattenuating crescent sign. Radiology 1999;211:37-8.

2 Vu KN, Kaitoukov Y, Morin-Roy F, et al. Rupture signs on computed tomography, treatment, and outcome of abdominal aortic aneurysms. Insights Imaging 2014;5:281-93.

3 Mehard WB, Heiken JP, Sicard GA. High-attenuating crescent in abdominal aortic aneurysm wall at CT: a sign of acute or impending rupture. Radiology 1994;192:359-62. 
Copyright 2018 BMJ Publishing Group. All rights reserved. For permission to reuse any of this content visit http://group.bmj.com/group/rights-licensing/permissions.

BMJ Case Report Fellows may re-use this article for personal use and teaching without any further permission.

Become a Fellow of BMJ Case Reports today and you can:

- Submit as many cases as you like

- Enjoy fast sympathetic peer review and rapid publication of accepted articles

Access all the published articles

- Re-use any of the published material for personal use and teaching without further permission

For information on Institutional Fellowships contact consortiasales@bmjgroup.com

Visit casereports.bmj.com for more articles like this and to become a Fellow 